\title{
CONDIÇÕES E RELAÇÕES DE TRABALHO NO SERVIÇO PÚBLICO: O CASO DO GOVERNO LULA
}

\author{
Darcilene Cláudio Gomes \\ Leonardo Barbosa e Silva \\ Sidartha Sória
}

\section{RESUMO}

Este artigo tem por objetivo inventariar as diversas iniciativas do governo Lula (2003-2010) no que diz respeito à formatação de uma política de recursos humanos e, dessa forma, verificar se houve melhoria das condições e relações de trabalho no setor público brasileiro. A partir dos anos 1990 e na contramão do grande crescimento do emprego público nas seis décadas anteriores, a adesão dos governos brasileiros aos princípios do "Consenso de Washington" destaca o funcionalismo como ponto fundamental na agenda das reformas necessárias à retomada do crescimento econômico. Os tais governos tenderam a tratar o emprego público como um problema fiscal e atuaram no sentido de restringir sua dimensão. Em simultâneo, as condições e relações de trabalho apresentaram-se mais precarizadas (evidenciadas pela ausência de reajuste salarial; o crescimento de formas variáveis de remuneração; ampliação do quadro de temporários e terceirizados e com a postura autoritária diante da representação sindical). Por meio de pesquisa documental e bibliográfica, poder-se-á perceber que a reestruturação de várias carreiras, a retomada dos concursos, a criação da Mesa Nacional de Negociação Permanente, a reforma previdenciária e os reajustes seletivos das remunerações manifestam a ambigüidade como marca fundamental das políticas de recursos humanos. Isto porque, a um só tempo, os avanços nas condições de trabalho do servidor público foram sempre acompanhados pela manutenção de parte da agenda conservadora dos anos 1990, sobretudo no que diz respeito à reprodução de limites fiscais rigorosos.

PALAVRAS-CHAVE: emprego público; condições de trabalho; negociação coletiva.

\section{INTRODUÇÃO ${ }^{1}$}

A partir dos anos 1930, com a estruturação do Estado e ampliação de suas funções para além das atividades consideradas típicas, o Brasil experimentou grande crescimento do emprego público. No período, foram expandidos os serviços sociais e a produção de bens realizada pelo Estado, movimento que se repetiu nas décadas seguintes. Mas apesar do crescimento, o emprego público no país não alcançou dimensão similar ao contabilizado nos países centrais. Enquanto a relação entre emprego público e população economicamente ativa (PEA) era de 16,6\% em 1982 nos EUA,

\footnotetext{
1 A pesquisa em que este trabalho insere-se é fruto de uma parceria entre a Fundação Joaquim Nabuco e o Departamento de Ciências Sociais da Universidade Federal de Uberlândia. Os autores agradecem aos pareceristas anônimos da Revista de Sociologia e Política por seus comentários.
}

no Brasil o mesmo número era 8,16\% em 1986 (CARVALHO FILHO, 2002).

Não obstante a estabilidade na relação emprego público e emprego total, observou-se piora nas condições de trabalho dos servidores públicos nos países centrais a partir dos anos 1970, os quais experimentaram mudanças na estrutura de remuneração (com crescimento da parcela variável dos rendimentos), intensificação do trabalho e precarização do vínculo (considerado como ampliação dos empregos temporários).

Por sua vez, nos anos 1990 o Brasil adere ao receituário do denominado "Consenso de Washington", e a questão do funcionalismo público passa a figurar na agenda das reformas necessárias à retomada do crescimento econômico. Os governos ao longo dos anos 1990 tenderam a tratar o emprego público como um problema fiscal e atuaram no sentido de restringir sua dimensão e/ou seus custos. Os 
dados disponíveis na Secretária de Recursos Humanos do Ministério do Planejamento e Orçamento mostram que o objetivo de redução do quadro de funcionários públicos foi alcançado no período, ao menos em âmbito federal, ainda que, possivelmente, em menor proporção em relação ao almejado. Em simultâneo, as condições e relações de trabalho apresentaram-se mais precarizadas. Embora sejam relativamente poucos os estudos que abordem o tema, algumas evidências apontam nesse sentido, entre as quais: a ausência de reajuste salarial para boa parte do funcionalismo público; o crescimento de formas variáveis de remuneração; ampliação do quadro de temporários e terceirizados; postura autoritária em relação às organizações sindicais.

Com o governo Lula, alguns documentos e determinadas ações dirigidas ao funcionalismo público (como a instituição da Mesa Nacional de Negociação Permanente) pareciam indicar o início de um novo tipo de relacionamento entre governo e trabalhadores do serviço público. Por outro lado, a Reforma da Previdência aprovada no primeiro ano do governo foi um indício que o período seria marcado por aparente ambigüidade no tratamento dispensado aos trabalhadores do setor público (ademais, como em boa parte das iniciativas do governo).

Nesse sentido, é importante inventariar as diversas iniciativas do atual governo no que diz respeito à formatação de uma política de recursos humanos (aqui compreendida como um guia para questões relativas ao recrutamento, ao plano de carreiras, ao treinamento, a avaliação de desempenho, a política de remuneração, saúde e segurança do trabalhador e relações de trabalho) e, dessa forma, verificar se houve melhoria das condições e relações de trabalho no setor público brasileiro. O objetivo deste artigo é o de lançar luzes sobre algumas das iniciativas relativas à implementação da política de recursos humanos, especialmente a instituição da Mesa Nacional de Negociação Permanente e a questão da remuneração. Convém mencionar que o estudo ora apresentado integra uma ampla pesquisa, que começa a dar os primeiros passos, sobre as condições de trabalho no serviço público enfocando duas carreiras específicas: docentes das instituições federais de ensino superior e a de pesquisador em ciência e tecnologia.
O artigo está dividido em dois itens, além da introdução e considerações finais. O primeiro trata da reforma do serviço público no Brasil na década de 1990. O segundo enfocará o governo do Presidente Luis Inácio Lula da Silva.

\section{A REFORMA DO SERVIÇO PÚBLICO NOS ANOS $1990^{2}$}

As reformas econômicas instituídas nos anos 1990, que visaram adaptar a economia brasileira ao panorama internacional, caracterizado por uma crescente globalização financeira e produtiva, tiveram impactos negativos sobre o mercado de trabalho nacional (BALTAR, 2003; DEDECCA, 2003; QUADROS, 2003; GOMES, 2009).

Em primeiro lugar, deve-se ressaltar que as taxas de ampliação da ocupação $(1,8 \%$ ao ano, entre 1992-2001) foram inferiores às do crescimento da PEA, que seguiu expandindose em ritmo acelerado $-2,1 \%$ ao ano, entre 1992 e 2001 (como resultado da continuidade do movimento de ingresso feminino no mercado de trabalho, especialmente da mulher adulta).

Com a ocupação crescendo menos do que a PEA, as taxas de desemprego experimentaram um salto e alcançaram números ainda não vistos na economia brasileira (7,2\% em 1992 para $10,1 \%$ em 2001). O segmento mais afetado foi o juvenil, que amargou os mais elevados níveis de desemprego (em 2001, por exemplo, o desemprego juvenil feminino alcançou a marca de $23,1 \%)$. As mulheres, por sua vez, representavam a maioria dos desempregados (54,4\% do estoque de desempregados em 1999 era do sexo feminino). Entretanto, o aumento do desemprego alcançou todos os grupos sociais, segundo qualquer atributo pessoal (GOMES, 2009).

O baixo dinamismo na geração de postos de trabalho abateu-se com mais força sobre o emprego formalizado, que, além de perder participação no total da ocupação (em 1989 representava 51,9\% e em 1999 passou a

2 Os dados sobre população economicamente ativa, população ocupada e desocupada foram extraídos a partir dos microdados da Pesquisa Nacional por Amostra de Domicílios (IBGE, 2009). 
representar 42,8\%), ficou mais heterogêneo em decorrência, por exemplo, da disseminação das novas modalidades de contratação instituídas nos anos 1990 (como as várias modalidades de contratação temporária e o contrato em tempo parcial). Em simultâneo, notou-se um crescimento dos segmentos considerados pouco estruturados do mercado de trabalho: o emprego sem registro, o trabalho por conta própria e o serviço doméstico (idem).

O setor público empreendeu importante ajuste no pessoal ocupado, os dados apontam relativa estabilidade no número de empregados públicos, mas considerando o nível de governo observou-se uma queda nos empregos na esfera federal e estadual na década de 1990 . O ajuste no emprego público só não ganhou maiores proporções por ter sido parcialmente compensado pelo aumento do emprego nos municípios, devido à descentralização da execução das políticas sociais (que ganhou força após a promulgação da Constituição Federal de 1988) e à criação de novos municípios (Abrúcio e Ferreira da Costa apud CARVALHO FILHO, 2002).

$\mathrm{Na}$ esfera estadual, a redução dos empregados tem relação com a privatização dos bancos e empresas estaduais e a venda da participação acionária dos estados em outras empresas, além da alegada necessidade de cortar os gastos $^{3}$ (CARVALHO FILHO, 2002).

No plano federal, as primeiras medidas vieram com o governo Collor, a saber: fechamento de órgãos, privatização e demissão sumária de funcionários. Todavia, as restrições impostas pela legislação impediram o ajuste no funcionalismo pela via da demissão. Nesse sentido, a saída foi limitar o ingresso de novos servidores, o que foi alcançado por meio da contenção-suspensão dos concursos públicos (idem). No governo Cardoso a situação do funcionalismo público ganhou melhor elaboração, como evidenciam vários documentos e publicações organizadas pelo recém-criado Ministério da Administração Federal e da Reforma do Estado (MARE), além da própria criação desse ministério.

3 Todas as medidas têm relação com a negociação das dívidas dos estados (CARVALHO FILHO, 2002).
O Plano Diretor da Reforma do Aparelho do Estado (MARE, 1995), doravante denominado Plano Diretor, foi a síntese dos diagnósticos e proposições do governo Fernando Henrique Cardoso para a reforma do Estado brasileiro. O documento concentra-se detidamente no aparelho de Estado, ou seja, na administração, nos recursos humanos, nos serviços e na forma de propriedade e representa o embrião das modificações legais inscritas nas emendas constitucionais n. 19 e $\mathrm{n}$. 20, ambas aprovadas em 1998.

Sobre os recursos humanos, o documento levanta pontos razoáveis, como o destaque à ausência, na legislação, de uma política "[...] coerente com as necessidades do aparelho de Estado" (idem, p. 27). Em contrapartida, não apresenta uma proposta consistente e completa de política para o segmento e nem mesmo o que considera ser o adequado.

O Plano Diretor presta-se a oferecer um diagnóstico crítico ao existente, centrando atenção em alguns aspectos e ignorando outros. Por exemplo, sobre a forma de ingresso no serviço público exclusivamente via concursos, posicionase de modo crítico. De acordo com o documento, tal critério impõe uma rigidez que não se coaduna com o princípio da competência e impediria o "recrutamento direto no mercado" ou outras formas mais flexíveis de contratação (como a do regime celetista). O Plano Diretor aponta a inexistência de uma estrutura de carreiras que abarque todo o funcionalismo; cerca de $50 \%$ do pessoal civil estatutário estaria fora de carreiras específicas, sendo poucas as "verdadeiras" carreiras existentes (assim consideradas entre os civis apenas a Diplomacia e o Magistério, por possuírem amplitude significativa entre o piso e o teto salarial). O próprio concurso, de periodicidade não regular e sem a avaliação devida sobre a necessidade de quadros, inviabilizaria a organização de carreiras específicas.

Sobre as relações de trabalho, o documento argumenta que a legislação que a regula é "protecionista" e inibe "o espírito empreendedor", mas não aprofunda o entendimento de tais qualificações. Defende a necessidade de avaliar o desempenho do funcionalismo e premiar aqueles que obtiverem atuação destacada. Menciona a ausência de políticas de qualificação e de atualização permanente do quadro. No que diz respeito à remuneração, cita a ausência de uma 
política que seja "condizente com a valorização do exercício da função pública", caracteriza o sistema remuneratório como "desequilibrado", no qual somente algumas carreiras específicas logram perceber rendimentos satisfatórios. Reconhece, ainda sobre a questão da remuneração, que os profissionais com maior nível de escolaridade percebem rendimentos menores no serviço público comparativamente ao setor privado. O contrário é observado com as funções operacionais, as quais são mais bem remuneradas pelo setor público vis-à-vis o setor privado. Já a questão da atenção à segurança e saúde dos servidores aparece de forma bastante rápida no final do documento, sem que se apresente algum diagnóstico e diretrizes para atuação do Estado. Outro aspecto que merece referência é o Regime de Previdência do Servidor Público. Mostra-se o crescimento das despesas com os inativos, seu caráter injusto e desequilibrado e argumenta-se sobre a difícil sustentação financeira do sistema.

Ao que parece, a discussão feita no Plano Diretor relativamente ao funcionalismo foi balizada pela necessidade de ajuste nas contas públicas. Os servidores do Estado aparecem, dessa forma, como um problema fiscal. Mas, cabe mencionar, não há no Plano Diretor um diagnóstico de excesso de quadros, de "inchaço" da máquina pública como se tornou corrente apontar. Na verdade, o documento assinala má distribuição do funcionalismo, com maior concentração de servidores em níveis operacionais e deficit em atividades finalísticas. Apontou-se, ainda, uma tendência de queda no número de funcionários públicos ativos, o que pôde ser observado a partir de 1990.

A Emenda Constitucional (EC) n. 19/98 materializa boa parte das discussões apresentadas no Plano Diretor, ainda que muitos artigos careçam de lei complementar para sua efetivação. O Regime Jurídico Único, alvo de críticas em diversas passagens do Plano Diretor, foi facultado. Alterou-se o prazo de conquista da estabilidade (de dois para três anos), a qual ficou condicionada à avaliação especial de desempenho realizada por comissão instituída para tal finalidade. Ainda sobre a questão da estabilidade, acrescentaram-se duas situações que implicariam a perda do cargo: avaliações negativas de desempenho a serem realizadas periodicamente e excesso de despesa
(Lei Complementar n. 9 801/99). Sobre a remuneração estabelece: data-base; a obrigatoriedade de revisão anual (Lei n. 10 331/ 2001); tetos (o subsídio dos ministros do Supremo Tribunal Federal) e a quebra de isonomia. Não chega a legislar sobre as relações de trabalho, deixa, por exemplo, o direito de greve para ser definido, como observado na Constituição Federal de 1988, em lei específica.

A EC n. 20 trata de um dos temas mais recorrentes no Plano Diretor: o da reforma previdenciária. Dentre os itens mais importantes da reforma prevista na emenda, no que tange aos funcionários públicos, têm-se a instituição: $i$ ) da aposentadoria por tempo de contribuição em substituição ao tempo de serviço; ii) da idade mínima para a aposentadoria (60 anos para os homens e 55 para as mulheres); iii) da exigência de tempo mínimo de exercício no serviço público (dez anos) e na função (cinco anos); $i v$ ) da extinção a aposentadoria proporcional por tempo de serviço (MATIJASCIC, 2002). Deve ser mencionado que a reforma aprovada teve natureza paramétrica, não se viabilizou uma reforma de caráter estrutural ${ }^{4}$ como a observada em outros países latino-americanos, mas apresentou traços claros de descontinuidade em relação ao conceito de seguridade social inscrito na Constituição Federal de 1988 (MARQUES, 2000; MATIJASCIC, 2002).

Além das emendas à Constituição, outras iniciativas legislativas atingiram o funcionalismo público no período. Cabe registro a introdução da contribuição de aposentados e pensionistas ao sistema previdenciário (Lei n. 9 783/99, cassada pelo Supremo Tribunal Federal no mesmo ano, mas atualmente em vigor ${ }^{5}$ ).

Analisando as diretrizes do Plano Diretor e das ECs n. 19 e n. 20, pode-se dizer que, na dimensão das reformas que atingiram os "recursos humanos", a questão do funcionalismo foi tratada de modo contábil, como imperativo ao necessário ajuste fiscal, este tão caro aos gestores públicos

\footnotetext{
${ }^{4}$ Pois se manteve estatal, unificada, fundada em benefícios definidos e na solidariedade intergeracional. (MATIJASCIC, 2002).

5 Lei n. $10887 / 04$. Todavia, está em discussão no Congresso um projeto de emenda constitucional (PEC
} n. 555/2006) que elimina a contribuição. 
na década de 1990. A dimensão social, isto é, aquela voltada para a discussão sobre a função do aparelho de Estado diante das demandas sociais, não mereceu maior atenção por parte dos mesmos governantes.

Não são numerosos os estudos que apontam o resultado das reformas direcionadas ao serviço público, e não se conhece a efetividade de muitas medidas adotadas. Sabe-se, como já mencionado, que o contingente de funcionários públicos ativos foi reduzido (MPOG/SRH, 2010a), em grande medida pela corrida à aposentadoria (motivada pela reforma da previdência) e da não reposição de servidores ${ }^{6}$. A perda da função pública determinada por desempenho insatisfatório ainda não foi regulamentada 7 .

O debate sobre o "inchaço" do setor público muitas vezes oculta uma discussão de grande importância: a que diz respeito ao comprometimento de serviços essenciais de provisão integral/parcial realizados pelo Estado. Dito de modo diverso, a redução do número de servidores públicos, dependendo da forma como for realizada, pode afetar a provisão de serviços de saúde, educação, assistência social, previdência etc. Há indícios de que houve comprometimento no fornecimento de muitos desses serviços. A universidade pública é um exemplo. Não houve reposição, no mesmo ritmo, dos professores que se aposentaram. Os dados da PNAD (IBGE, 2009) mostram, por exemplo, queda de quase $19 \%$ no número de professores do ensino superior entre 1995 e 1999 (PESSOA, 2003). Os denominados "substitutos" (temporários com contrato especial ${ }^{8}$ ) conseguiram apenas minimizar o problema, mas que ficou longe de uma solução adequada. Segundo o documento "Breve Diagnóstico da Administração Pública Federal",

\footnotetext{
6 Nesse campo as iniciativas foram variadas e tiveram início com o governo Collor e foram acentuadas no governo Cardoso, tais como: demissões de não efetivos, limitações de novas contratações e privatização das empresas estatais. No governo Cardoso criou-se, ainda, o Plano de Demissão Voluntária (PESSOA, 2003).

7 Projeto de Lei Complementar n. 248/98 (em tramitação).

8 Além de contratados por tempo determinado, a jornada dos substitutos é mais elevada do que dos professores efetivos e a remuneração muito aquém da percebida pela categoria.
}

elaborado pela Casa Civil da Presidência da República em 2004, havia um "[...] gravíssimo déficit institucional verificado em áreas estratégicas do governo, tais como: Receita Federal [...], Fiscalização Agropecuária e do Trabalho, Reforma Agrária, Proteção do Patrimônio Histórico, Propriedade Industrial, Polícia Federal, Secretaria de Previdência Complementar [...] entre outros" (Casa Civil apud UEMA, 2005).

Sobre a remuneração foram privilegiadas as gratificações (institucionais e/ou individuais) como instrumento de revisão remuneratória, em detrimento de reajustes no vencimento básico. As gratificações já eram utilizadas como parte da remuneração dos servidores (composta por vencimento básico, indenizações, gratificações e adicionais), mas, ao que parece, seu emprego de modo mais generalizado e em substituição aos reajustes salariais ocorreu a partir dos anos 1990. Uma forte indicação a esse respeito é a crescente distância entre o vencimento básico e o total da remuneração, em alguns casos as gratificações correspondiam a mais de $90 \%$ do rendimento dos servidores (DIEESE, 2005).

Sobre as relações de trabalho não foram registrados avanços significativos no período. As relações entre governo e representação dos trabalhadores foram tensas durante toda a década de 1990. Os primeiros sinais da dificuldade de negociação já apareceram no início do governo Cardoso com a greve dos petroleiros, a qual foi reprimida de forma impetuosa com demissão de trabalhadores, ocupação de refinarias pelo Exército e a imposição do pagamento de multas milionárias aos sindicatos (medida imposta pelo Tribunal Superior do Trabalho após julgar a greve como abusiva). Sem entrar no mérito da questão, pretende-se chamar a atenção para a forma como se estabeleceu o relacionamento entre governo e representação sindical.

As informações disponíveis precisam ser mais bem organizadas, há muito que ser esclarecido e aprofundado sobre o tema. É preciso buscar compreender de forma global o ocorrido com o funcionalismo público durante os anos 1990. Esse exercício é importante, pois auxiliará na compreensão dos avanços (e se existem) e das permanências do tratamento dispensado aos servidores públicos na década passada e nos anos 2000. 


\section{O SERVIÇO PÚBLICO E O GOVERNO LULA}

As expectativas do funcionalismo público eram, de forma geral, muito positivas em relação ao governo Lula da Silva, devido à história de formação do Partido dos Trabalhadores, das bases sociais que deram sustentação à agremiação ao longo de sua existência e da relação mantida com os sindicatos e movimentos sociais.

Segundo o documento Gestão pública para um Brasil de todos (BRASIL, 2003), o governo Lula teria como propósito reestruturar o serviço público a partir de duas vertentes: o de fazer frente às demandas sociais e tornar o Estado mais "eficiente, inclusivo e eqüitativo". Dentro de tal perspectiva inclui-se o funcionalismo público, isto é, como operador da reorganização desejada. Para tanto, são propostas várias medidas que visam fomentar uma política de recursos humanos.

O mesmo documento defende, no que diz respeito à estruturação da administração pública, a realização de determinadas "intervenções", quais sejam: recomposição da força de trabalho no setor público; redesenho dos sistemas de cargos, carreiras, benefícios e concursos; realinhamento de salários; definição de política de capacitação técnica e gerencial permanente de servidores; promoção de ações visando a saúde ocupacional e o redesenho de estruturas e processos de trabalho (idem).

Observa-se, desse modo, que boa parte das ações materializadas, no tocante ao funcionalismo público, já estavam anunciadas desde o início do governo, ainda que de modo superficial, mas aparentemente em direção ao esperado/ demandado pelos servidores.

Entretanto, a Reforma da Previdência aprovada no início do governo, a qual avançou em pontos que a EC n. 20 não havia conseguido consenso, foi um indício que o período seria marcado por aparente ambigüidade no tratamento dispensado aos trabalhadores do setor público ${ }^{9}$. Além da reforma, a defesa da contribuição dos aposentados ao regime previdenciário foi outra importante

9 Ainda que os pilares da reforma já estivem presentes no programa de governo do então candidato Lula (MARQUES \& MENDES, 2004). medida que se contrapôs aos interesses da categoria $^{10}$.

Aos poucos, ao longo dos dois mandatos, o Governo encaminhou projetos de lei visando estruturar uma "política de recursos humanos", na linha do mencionado no documento Gestão pública para um Brasil de todos. Pode ser citado, por exemplo, o Decreto n. 5707 de 2006 que instituiu a "Política Nacional de Desenvolvimento de Pessoal", cujo objetivo é o de estabelecer uma política de capacitação permanente dos servidores. Outro exemplo é o da Lei n. 11 784/08 que define diretrizes gerais do sistema de avaliação de desempenho. Sobre a estruturação/criação de carreiras e tabelas remuneratórias a legislação é extensa (para citar algumas: Lei n. 11 784/08; n. 11 776/08; n. 11 890/08; n. 11 355/06; n. 11 907/ 09). Ainda sobre as carreiras foi instituído pela Lei 11 890/08 o Sistema de Desenvolvimento na Carreira (Sidec), que estabelece regras de progressão e promoção para algumas carreiras definidas em lei (MORAES, SILVA \& COSTA, 2008; BRASIL, 2009).

Outro ponto que merece destaque é a recomposição do contingente de funcionários públicos por meio da maior oferta de concursos. Segundo MPOG/SRH (2010a), entre 2003 e dezembro de 2009 ingressaram no serviço público federal $118933^{11}$ trabalhadores, totalizando 601 117 servidores ativos no poder Executivo em dezembro de $2009^{12}$. Interrompeu-se, dessa

10 Pode ser listada outra iniciativa no mesmo sentido: o envio pelo poder Executivo do Projeto de Lei Complementar n. 1/07 que restringe os gastos com pessoal (em tramitação).

11 Segundo nota na publicação MPOG/SRH (2010a) o quantitativo de ingresso no serviço público não é um número exato e não pode ser diretamente relacionado ao quantitativo de vagas ofertadas em concursos públicos. Primeiro, por se tratar de uma posição do dia em que a tabela foi confeccionada, pois o sistema utilizado para obtenção dos dados é alimentado diariamente. Segundo, pelo fato do sistema não considerar como ingressante aquele que já possuía cargo no serviço público. De qualquer forma, o número pode ser considerado uma boa estimativa da evolução dos ingressantes no serviço público.

12 Os dados sobre o quantitativo de servidores variam de acordo com o momento da extração de dados do sistema, pois a força de trabalho do setor público está em constante movimento (devido à ocorrência de aposentadorias, vacâncias, términos de contrato). 
forma, a trajetória de redução do funcionalismo público iniciada no início da década de 1990.

Embora tenha crescido o número de servidores federais, não se alcançou o patamar observado antes de 1996. Segundo Moraes, Silva e Costa (2008) para a recomposição foram priorizados setores com maiores deficits (como a educação) e segmentos considerados importantes segundo o projeto de desenvolvimento em curso (agências reguladoras, para ampliação dos programas sociais, ampliação do quadro do ciclo de gestão, reforço dos órgãos de controle; fortalecimento da Polícia Federal etc.). Outras diretrizes em relação à recomposição do quantitativo foram: a substituição de funcionários com baixa qualificação por quadros técnicos com escolarização mais elevada e a substituição dos trabalhadores terceirizados.

Em um primeiro olhar os dados tendem a confirmar as prioridades na recomposição dos quadros. Observa-se que de cada dez ingressantes no serviço público entre 2003 e 2009 , quatro eram docentes do ensino superior ${ }^{13}$ e servidores técnico-administrativos das instituições federais de ensino superior ${ }^{14}$ - o que demonstra a prioridade dada à área educacional. $\mathrm{O}$ aumento do número de trabalhadores, nesse caso, responde à política de expansão das universidades públicas (com ampliação das universidades existentes e abertura de novos campi). Os demais cargos ou carreiras privilegiados necessitam ser avaliadas de modo mais detalhado. Uma hipótese é que foram atendidas carreiras com maior poder de barganha.

A maior novidade, no entanto, foi a instituição da Mesa Nacional de Negociação Permanente (MNNP), a qual pretendeu inaugurar um novo momento das relações de trabalho no serviço público. O governo Lula anunciou, desde os seus primeiros dias, que privilegiaria a via negocial para a resolução das dissensões dentro das quais um governo se vê mergulhado durante seu mandato. Rivalizando com as gestões anteriores, sobretudo com aquelas que foram presididas por Fernando

13 Os quais representam em média $77 \%$ dos docentes ingressantes no serviço público federal no período 2003 e 2009.

14 Dados retirados de MPOG/SRH (2010a).
Henrique Cardoso, o governo comprometeu-se a não criminalizar, tampouco optar pelo antagonismo em relação às demandas dos movimentos sociais, sindicais ou não. A imagem de grande negociador ou de entusiasta da negociação parece ter sido consolidada (GOMES, 2006).

Esse parece ser o entendimento também do próprio mandatário do poder Executivo Federal para implementar um sistema de resolução de conflitos entre a Administração Pública Federal e o funcionalismo representado pela Mesa Nacional de Negociação Permanente (MNNP)

A Mesa foi inaugurada em 2003 e seus objetivos estão declarados em seu regimento. Lá se pode perceber que, a um só tempo, intenta-se criar um canal duradouro para o tratamento dos conflitos e das demandas dos servidores da administração direta, fundacional ou autárquica, sempre em busca de uma saída negociada para os possíveis impasses. Bem como permitir que as relações de trabalho sejam abordadas de modo totalizante dentro do serviço público, no que tange à sua gestão, funcionamento da máquina, qualidade, carreira, remunerações, direitos, participação etc. É importante ressaltar que, dentro dos marcos regimentais, a Mesa representa enorme avanço. Além de estabelecer uma importante ferramenta de diálogo, também institucionaliza um espaço para que o trabalhador da administração pública, por meio de seus representantes, pense o Estado e seu aparelho. Reconhecendo e superando as demandas corporativas, setoriais ou categoriais, inegavelmente importantes, a Mesa inaugura uma dimensão inédita, isto é, ela assume a tarefa de repensar a administração pública não contra seus funcionários, mas com eles.

As temáticas abordadas serão apreciadas e deliberadas por um plenário dividido em duas bancadas, a governamental e a sindical, representando as forças e os interesses envolvidos. A bancada governamental é composta pelas pastas diretamente afeitas ao conteúdo da Mesa ${ }^{15}$. Do outro lado, a bancada sindical comporta até 18 entidades de classe no âmbito nacional,

15 Ministérios do Planejamento, Orçamento e Gestão (MPOG), Previdência Social, Trabalho e Emprego, da Fazenda, a Casa Civil e a Secretaria Geral da Presidência. 
representadas por delegados indicados e observadores. No momento da implementação da mesa, a bancada sindical ainda não se encontrava completa, mas poderia, a qualquer momento, preencher as cadeiras restantes, juntando-se às entidades presentes desde sua fundação ${ }^{16}$.

O funcionamento paritário será acompanhado pelo respeito aos princípios constitucionais que regulam a administração pública e o estado de direito (participação e liberdade sindical) e aos preceitos suplementares que garantem a democracia na negociação (a ética, o acesso à informação, a obrigatoriedade da busca pela negociação etc.). Erguida a moldura dos princípios e preceitos, a Mesa entra em efetivo exercício. Os debates e deliberações podem ocorrer na Mesa Central ou nas mesas setoriais (política salarial, seguridade, direitos sindicais e negociação coletiva etc.).

O conteúdo regimental busca, como se pode ver, a todo o momento, reforçar o componente negocial, instigando seus membros a insistirem nesta via. A condução dos conflitos é feita por leitos pensados para priorizar a solução consensual.

Não se pode considerar ainda que o efetivo exercício da Mesa signifique a ratificação da Convenção 151 da Organização Internacional do Trabalho (OIT) que estabelece a negociação coletiva no setor público, pois a mesma não se vê como obrigatória a partir de um instituto legal. $\mathrm{Ou}$ seja, diferentemente do setor privado, no qual a negociação coletiva entre capital e trabalho é

16 São elas: Sindicato Nacional dos Docentes das Instituições de Ensino Superior (Andes-SN); Sindicato Nacional dos Trabalhadores em Fundações Públicas Federais de Geografia e Estatística (Assibge); Confederação Nacional dos Trabalhadores em Seguridade Social (Cntss);Confederação dos Trabalhadores no Serviço Público Federal (Condsef); Central Única dos Trabalhadores (CUT); Federação de Sindicatos de Trabalhadores das Universidades Brasileiras (Fasubra); Federação Nacional dos Auditores Fiscais da Previdência Social (Fenafisp); Federação Nacional dos Trabalhadores do Judiciário Federal e Ministério Público da União (Fenajufe); Federação Nacional dos Sindicatos de Trabalhadores em Saúde, Trabalho, Previdência e Assistência Social (Fenasps); Sindicato Nacional dos Servidores Federais da Educação Básica e Profissional (Sinasefe); Sindicato dos Servidores do Poder Legislativo Federal e do TCU (Sindilegis); Sindicato Nacional dos Auditores Fiscais da Receita Federal (Unafisco). obrigatória por lei, a Mesa ainda se coloca como espaço de formulação e deliberação facultado às entidades. Não se estabeleceu, ainda que a Constituição Federal já o sinalize, a data base para o servidor ou o instituto imperativo para que o governo receba a pauta de reivindicações e abra negociação. Na verdade, para que se legalize a negociação coletiva e o direito de greve no setor público, é necessária a alteração do artigo n. 37 da Constituição Federal, o que exige a tramitação de uma emenda. Mas foi por meio das discussões da Mesa que o governo federal amadureceu o entendimento necessário para o envio de um projeto de lei que regulamenta a referida convenção.

A instituição da Mesa não é obra inovadora do atual governo. Experiências frustradas em gestões anteriores parecem ter fertilizado o modelo vigente. Ao que tudo indica, a MNNP foi inspirada na Mesa Nacional de Negociação do Sistema Único de Saúde (SUS), instituída em maio de 1993, por meio da Resolução n. 52 do Conselho Nacional de Saúde. Sob a chefia do Ministro Jamil Haddad, a mesa foi inaugurada com composição paritária (empregadores e servidores públicos) e destinada a enfrentar as demandas trabalhistas acerca da remuneração, jornada, carreira, direitos e mecanismos de gestão dos recursos humanos. A ausência de regularidade das reuniões da mesa não permitiu grandes avanços.

Sua reinstalação, no entanto, ocorreu em 1997 em resolução superior do mesmo Conselho (Resolução n. 229), com redução de 11 para nove o número de representantes de cada grupo de interesse (administração pública e servidores), todavia, assolada pela mesma irregularidade, novamente desaguou na interrupção das suas atividades. Foi somente em meados de 2003, em sua terceira versão, que a mesa ganhou efetividade. Portadora de uma nova composição e denominação (Mesa Nacional de Negociação Permanente do SUS) ela constituiu-se como um fórum paritário que reúne gestores e trabalhadores indicado para a solução dos conflitos típicos das relações de trabalho. Não obstante seus objetivos concentrem-se nos processos de negociação pertinentes às relações de trabalho, encampam também a contribuição para o pleno funcionamento do SUS. Desse modo, as Mesas de 1993 e 1997, apesar de náufragas, constituíram existências prévias de objetivos comuns àquelas que se instalaram em maio de 2003 (MNNP) e em junho de 2003 (MNNP-SUS). 
Sabidos os marcos regimentais e a possível origem histórica da Mesa, torna-se relevante, neste instante, debruçar-se sobre seu efetivo funcionamento. Far-se-á tal esforço por meio dos depoimentos de suas bancadas constituintes, ou seja, da bancada governamental e da bancada sindical.

É importante destacar que o governo federal, em seu balanço das atividades do ano de 2004, nutria uma avaliação positiva desde o segundo ano de funcionamento da Mesa. Entendia ele, por meio do MPOG, que o avanço expressivo encontravase no estabelecimento de um novo padrão de relação de trabalho no serviço público brasileiro. Assim, atesta que "merece destaque especial a instalação das Mesas Setoriais de Negociação Permanente, a partir da criação da Mesa Nacional de Negociação Permanente no Serviço Público Federal, grande avanço na construção de um modelo democrático, participativo e includente de relações do trabalho no setor público brasileiro" (BRASIL, 2007).

Já ao final de 2007, o mesmo MPOG divulgou em seu sítio na Internet uma nova avaliação dos trabalhos da MNNP. Dele se depreende a visão governamental de que a mesa alcançou resultados importantes, seja por ter aberto o canal de negociação, seja por ter avançado no reajuste das remunerações dos servidores. Desse modo, o noticiário do MPOG afirma que "A Mesa passou, então, a ser a instância que recepciona e processa os debates acerca dos entendimentos sobre as reivindicações dos servidores, atualmente com um quadro formado por 1, 150 milhão de pessoas, entre ativos e inativos civis do Poder Executivo. 'As relações de trabalho são, historicamente, de natureza conflituosa, e o que a Constituição Federal coloca de novo de 1988 para cá é a de permitir que servidores públicos tenham acesso à organização sindical e, portanto, ao processo de negociação', esclarece Duvanier Ferreira, secretário de Recursos Humanos do Ministério do Planejamento, órgão central da administração pública federal. Segundo Duvanier Ferreira, as negociações significam, também, que qualitativamente as soluções são de outro nível. Entre 2003 e 2006, as remunerações dos servidores foram recompostas de forma que nenhuma categoria tivesse índices de reajustes abaixo da inflação acumulada no período, que foi de $28,9 \%$. 'Corrigimos distorções salariais e determinamos o pagamento de passivos que se arrastavam há vários anos, alguns há mais de 15 anos', afirma o ministro do Planejamento, Paulo Bernardo" (BRASIL, 2007).

Entretanto, o mesmo diagnóstico não resistiu muito tempo, pois a interrupção do funcionamento da mesa levou o próprio balanço oficial, anos depois, a apontar debilidades de grande monta. É importante dar relevo ao depoimento do Ministro Paulo Bernardo registrado no Boletim (BOLETIM ELETRÔNICO, 2007) destinado aos servidores públicos no qual destacou os avanços da MNNP ao estabelecer novo patamar nas relações trabalhistas entre governo e servidores, mas reconheceu igualmente os problemas em seu funcionamento e a necessidade de aperfeiçoar o mecanismo para a sua retomada. Atesta o Ministro que as negociações setoriais que passaram por cima da Mesa acabaram por gerar insatisfações recíprocas que agora as partes estão empenhadas em superar.

A interrupção da negociação ocorreu entre os anos de 2005 e 2007, por parte do governo federal que não possibilitou à Mesa a apreciação das demandas das entidades representativas dos trabalhadores e o cumprimento de alguns acordos selados em seu interior. Neste contexto, algumas entidades, como o Andes, retiraram-se da mesa. Entre as entidades que restaram existe o reconhecimento de que o mecanismo negocial deve ser recuperado e consolidado, no entanto será necessário superar a desconfiança produzida por anos de um funcionamento incompatível com os objetivos expressos em sua fundação. É o que se pode constatar ao se consultar o periódico da Confederação dos Trabalhadores no Serviço Público Federal (Condsef), um dos importantes membros da bancada sindical da Mesa, publicada em março de 2010. Afirma a Confederação que "[...] quase 8 anos depois da solenidade oficial que marcou a instalação das mesas de negociação no governo Lula, o sistema mostrou-se falho e o que é pior: além de não garantir o atendimento dos acordos e compromissos firmados em negociações legitimadas pelo próprio governo, a expectativa criada por reuniões - quase sempre infrutíferas - passou a gerar grande revolta e inconformismo nos servidores. Sentimentos que terminam por despertar na categoria a mesma necessidade legítima de se organizar, mobilizar, pressionar, enfim, lutar pelo cumprimento do que, 
afinal de contas, havia sido negociado com o governo" (CONDISEF, 2010).

Ressalta-se que os limites da MNNP não dizem respeito, exclusivamente, à incapacidade de consensualizar ou dirimir conflitos entre o funcionalismo e a administração pública federal. Para além da interrupção da negociação, sua própria realização estaria comprometida por bloqueios legais em tramitação no Congresso Nacional e de autoria do próprio poder Executivo Federal.

Importa salientar que a proposição do Projeto de Lei (PLP) n. 01/2007, responsável por reelaborar os limites de gasto com pessoal para o intervalo 2007-1016 ${ }^{17}$, estabeleceu o teto para possíveis reajustes salariais. Em que pese o fato de o referido PLP ainda tramitar na Câmara dos Deputados Federais, ele já produz impactos reais sobre a formulação do orçamento da União para 2009 , como se pode perceber no sítio da Secretaria de Orçamento Federal do Ministério do Planejamento, Orçamento e Gestão.

$\mathrm{Na}$ mesma linha, mas com tramitação mais adiantada está o Projeto de Lei do Senado (PLS) n. 611/2007. Como o PLP 01/2007, esse projeto estipula limites para os gastos da União, contudo o período indicado estende-se de 2010 a 2019 , enquadrando as despesas com pessoal de cada exercício fiscal ao valor do exercício anterior corrigido pelo Índice de Preços ao Consumidor Amplo (IPCA) e acrescido de $2,5 \%$ ou pela variação do crescimento do Produto Interno Bruto (PIB) (a escolha do critério se valerá pelo menor índice). Apresentado em 2007 e aprovado dois anos depois, o PLS n. 611/2007 seguiu para a Câmara dos Deputados, esperando igual aprovação.

Não obstante os projetos concorram ao apresentarem critérios de correção distintos para o gasto com pessoal, pode-se compreender que em qualquer cenário, isto é, aprovado um ou outro projeto, o que se terá de concreto é o estabelecimento de um limite real para qualquer negociação desenvolvida no seio da Mesa Nacional

17 Os limites são estabelecidos pelos gastos com pessoal do exercício fiscal anterior corrigido pelos índices do Índice Nacional de Preços ao Consumidor (INPC). de Negociação Permanente (DIEESE, 2007). Desse modo, a MNNP terá sua relevância esvaziada dada a impossibilidade de realizar o objetivo para o qual foi criada.

No que se refere à questão salarial, a obrigatoriedade da revisão anual, instituída pela EC n. 19, não foi uma medida efetivamente respeitada pelo atual governo, que parece ter buscado apenas atender aos desígnios da lei concedendo reajustes lineares modestos (ou nenhum) ao vencimento básico (1\% em 2003; $0 \%$ em 2003; $0,1 \%$ em 2005). Na esteira da reformulação das carreiras, pode-se observar a criação de dois tipos básicos de remuneração na estrutura salarial do serviço público, um na qual o vencimento é composto por apenas um valor fixo (subsídio) e outro composto por parcela fixa e outras parcelas variáveis. Cabe registrar que o segundo tipo predominava no governo anterior, com menor peso das gratificações em relação ao vencimento básico em parte das carreiras consideradas típicas de Estado (representava em torno de $67 \%$ da remuneração total).

Fazem jus ao primeiro tipo de remuneração algumas carreiras que foram especificadas na Lei n. 10 910/2004 e que são denominadas "típicas de Estado" (entre as quais: carreira de auditoria da Receita Federal, carreira de auditoria fiscal do trabalho, carreira de especialista do Banco Central, carreira de diplomata, carreiras de gestão governamental, carreira e cargos do IPEA e carreira de policial federal). Para os servidores que percebem subsídios há paridade entre ativos e aposentados. Para as demais carreiras a remuneração é composta por: vencimento básico, gratificações (condicionadas pelo desempenho pessoal e institucional) e restituição de titulação (para carreiras cuja natureza do cargo demanda a obtenção de títulos acadêmicos, como as de pesquisa em Ciência e Tecnologia e Docente). No caso dos aposentados, a gratificação por desempenho possui valor fixo e corresponde à metade do teto, o que implica perda salarial em relação aos ativos (exceto no caso dos docentes que conseguiram preservar a paridade). A título de exemplo, um pesquisador "Titular III" da carreira de C\&T, com doutorado, experimenta redução de aproximadamente $10 \%$ em seus vencimentos ao aposentar-se. Entre os pesquisadores da carreira do Instituto Brasileiro de Geografia e Estatística (IBGE) da classe 
"Especial III", com doutorado, a redução é ainda maior: cerca de $19 \%{ }^{18}$.

Entre as carreiras que percebem rendimentos variáveis, chama atenção a baixa participação do vencimento básico no total da remuneração, conforme pode ser visto na Tabela 1. Entre os docentes e pesquisadores em $\mathrm{C} \& \mathrm{~T}$, a progressão na carreira implica maior distanciamento entre o vencimento básico e o total. $\mathrm{O}$ vencimento básico para um docente da classe "Auxiliar 1" (com especialização) representa pouco mais da metade do total da remuneração, já para um docente "Titular" o vencimento básico equivale a um terço do rendimento total (percentual semelhante ao observado no topo da carreira de pesquisador em C\&T). Para os membros do Plano de Classificação de Cargos (PCC) o vencimento básico corresponde a pouco mais de $20 \%$ da remuneração efetivamente percebida.

TABELA 1 - VENCIMENTO BÁSICO, REMUNERAÇÃO TOTAL (R\$) E PESO DO VENCIMENTO BÁSICO (CARREIRAS SELECIONADAS, EM R\$; 2009)

\begin{tabular}{|c|c|c|c|c|}
\hline CARREIRA & CLASSE & $\begin{array}{c}\text { VENCIMENTO } \\
\text { BÁSICO (A) }\end{array}$ & $\begin{array}{c}\text { REMUNERAÇÃO } \\
\text { TOTAL (B) }\end{array}$ & $\begin{array}{c}\text { PESO VB } \\
\text { (B/A) }\end{array}$ \\
\hline Docente do ensino superior & Auxiliar $1^{*}$ & 1728,28 & 3077,28 & 56,2 \\
\hline Docente do ensino superior & Assistente 1 & 2001,86 & 4442,60 & 45,1 \\
\hline Docente do ensino superior & Adjunto 1 & 2318,71 & 6722,85 & 34,5 \\
\hline Docente do ensino superior & Associado $^{1}$ & 2758,26 & 9123,64 & 30,2 \\
\hline Docente do ensino superior & Titular & 3110,85 & 10446,81 & 29,8 \\
\hline Pesquisador C\&T & Assistente $\mathrm{I}^{*}$ & 2758,63 & 6456,87 & 42,7 \\
\hline Pesquisador C\&T & Assistente $\mathrm{I}^{\star \star}$ & 2758,63 & 7344,87 & 37,6 \\
\hline Pesquisador C\&T & Assistente $\mathrm{I}^{\star \star \star}$ & 2758,63 & 9168,87 & 30,1 \\
\hline Pesquisador C\&T & Adjunto I*** & 3144,98 & 10350,68 & 30,4 \\
\hline Pesquisador C\&T & Associado $I^{\star \star \star}$ & 3586,32 & 11690,76 & 30,7 \\
\hline Pesquisador C\&T & Titular $\mathrm{I}^{\star * *}$ & 4090,76 & 13214,36 & 31,0 \\
\hline Pesquisador C\&T & Titular III ${ }^{\star \star \star}$ & 4411,76 & 14175,82 & 31,1 \\
\hline Oficial de chancelaria & Al & 3769,63 & 5799,63 & 65,0 \\
\hline Oficial de chancelaria & Especial & 5279,61 & 8122,61 & 65,0 \\
\hline PCC IBGE - pesquisador & Al & 3475,87 & 8328,97 & 41,7 \\
\hline PCC IBGE - pesquisador & Especial III & 5558,82 & 14176,82 & 39,2 \\
\hline PCC INPI - pesquisador & Al & 3475,87 & 9367,87 & 37,1 \\
\hline PCC INPI - pesquisador & Especial III & 5558,82 & 14176,82 & 39,2 \\
\hline Perito Federal Agrário & Al & 2727,56 & 4547,56 & 60,0 \\
\hline Perito Federal Agrário & Especial III & 4126,31 & 6878,31 & 60,0 \\
\hline Fiscal Federal Agrário & Al & 4148,08 & 10648,08 & 39,0 \\
\hline Fiscal Federal Agrário & Especial IV & 6911,00 & 14900,00 & 46,4 \\
\hline PCC nivel superior & DI & 477,85 & 2076,41 & 23,0 \\
\hline PCC nível superior & A III & 625,32 & 2459,83 & 25,4 \\
\hline
\end{tabular}

FONTE: MPOG-SRH (2010a). Posição: julho de 2009.

NOTAS: 1. Considerando 100 pontos para as gratificações;

* Com especialização;

** Com mestrado;

*** Com doutorado.

18 Corresponde ao topo da carreira. A maior perda entre os pesquisadores da carreira do IBGE decorre do maior peso da gratificação de desempenho (cujo valor cai pela metade) em relação à restituição de titulação. 
A política de reajustes aparentemente segue as diretrizes do governo anterior, ou seja, privilegiouse a instituição/modificação de gratificações específicas em detrimento de reajustes mais significativos nos vencimentos básicos. Os servidores, de um modo geral, contaram com algum tipo de reajuste nos últimos anos, de modo distinto do governo Cardoso que atendeu o pleito de algumas poucas carreiras selecionadas.

A Tabela 2 apresenta o reajuste nominal tanto no vencimento básico quanto no total da remuneração para carreiras selecionadas entre 2002 e 2010. Observa-se que o percentual de correção salarial ficou muito acima da inflação no período, considerando qualquer índice inflacionário. Mesmo com reajustes generosos, é possível que parte dos servidores não tenha conseguido recuperar as perdas acumuladas ao longo dos anos 1990. De acordo com ICV/Dieese entre janeiro de 1995 e julho de 2010 a inflação acumulada foi de 228,28\%. Segundo estudo realizado pelo Dieese, entre os docentes do Ensino Superior as classes de Titular e Adjunto recuperaram as perdas acumuladas entre janeiro de 1995 e julho de 2010 e ainda asseguraram ganhos reais (pequenos). Já os auxiliares, da mesma carreira, permanecem com defasagem salarial (ADUFU, 2010).

TABELA2 - VENCIMENTO BÁSICO, REMUNERAÇÃO TOTAL, PESO DO VENCIMENTO BÁSICO E VARIA-

\begin{tabular}{|c|c|c|c|c|}
\hline CARREIRA & CLASSE & VENC. & REM. & PESODO \\
\hline Docente do ensino superior & Auxiliar $1^{*}$ & 506,69 & 1720,59 & 29,4 \\
\hline Docente do ensino superior & Assistente 1 & 692,25 & 2742,05 & 25,2 \\
\hline Docente do ensino superior & Adjunto 1 & 1026,44 & 4149,94 & 24,7 \\
\hline Docente do ensino superior & Titular & 1418,37 & 5437,76 & 26,1 \\
\hline Pesquisador C\&T & Assistente I* & 1484,75 & 2004,42 & 74,1 \\
\hline Pesquisador C\&T & Assistente $\mathrm{I}^{* *}$ & 1484,75 & 2524,08 & 58,8 \\
\hline Pesquisador C\&T & Adjunto I*** & 1712,03 & 3509,66 & 48,8 \\
\hline Pesquisador C\&T & Associado I*** & 1974,12 & 4046,95 & 48,8 \\
\hline Pesquisador C\&T & Titular $I^{\star * *}$ & 2276,32 & 4666,46 & 48,8 \\
\hline Pesquisador C\&T & Titular III*** & 2471,54 & 5066,66 & 48,8 \\
\hline Auditor Receita Federal & Al & 3059,65 & 5003,47 & 61,2 \\
\hline Auditor Receita Federal & Especial IV & 4885,37 & 7376,91 & 66,2 \\
\hline Auditor Fiscal do Trabalho & Al & 3059,65 & 5003,47 & 61,2 \\
\hline Auditor Fiscal do Trabalho & Especial IV & 4885,37 & 7376,91 & 66,2 \\
\hline Diplomata & Terceiro secretário & 3221,9 & 4832,85 & 66,7 \\
\hline Diplomata & Ministro de $1 .^{\circ}$ & 4647,37 & 6971,06 & 66,7 \\
\hline Oficial de chancelaria & Inicial I & 1786,83 & 2680,25 & 66,7 \\
\hline Oficial de chancelaria & Especial & 2482,96 & 3724,44 & 66,7 \\
\hline Gestão - EPPGG & AI & 2376,02 & 3564,03 & 66,7 \\
\hline Gestão - EPPGG & Especial IV & 4647,37 & 6971,06 & 66,7 \\
\hline PCC IPEA & Al & 2376,02 & 3564,03 & 66,7 \\
\hline PCC IPEA & Especial IV & 4647,37 & 6971,06 & 66,7 \\
\hline Polícial Federal - Delegado & Segunda**** & 462,91 & 7827,81 & 5,9 \\
\hline Policial Federal - Delegado & Especial & 548,89 & 9281,73 & 5,9 \\
\hline Fiscal Federal Agrário & Al & 1758,38 & 2637,57 & 66,7 \\
\hline Fiscal Federal Agrário & Especial III**** & 3519,57 & 5279,36 & 66,7 \\
\hline PCC nível superior & DI & 261,19 & 1183,09 & 22,1 \\
\hline PCC nivel superior & AIII & 559,85 & 1959,61 & 28,6 \\
\hline
\end{tabular}

FONTE: MPOG-SRH (2010a). Posição: dezembro de 2002.

NOTAS: 1. Considerando pontuação máxima para as gratificações.

* Com especialização;

** Com mestrado;

*** Com doutorado;

${ }^{* * * *}$ A carreira ganhou mais um nível inicial em 2010 (a classe terceira).

${ }^{* * * * \star}$ A carreira ganhou mais um nível para a classe especial em 2010. 
Para além do reajuste, boa parte das carreiras contou com recomposição de sua estrutura remuneratória. Chamam atenção as mudanças ocorridas na carreira de Policial Federal (composta por delegados e peritos criminais). Em 2002 o vencimento básico correspondia a apenas cerca de $6 \%$ do total da remuneração, a qual era composta por: vencimento básico, gratificação de operações especiais (GOE), gratificação de atividade executiva (GAE), indenização de habilitação policial (IHPF), gratificação de atividade, gratificação de compensação orgânica, gratificação de atividade de risco. Em 2006 a carreira foi reestruturada e seus ocupantes passaram a perceber subsídio (Medida Provisória N. 305/2006, convertida na Lei n. 11 358/2006). Os dados das tabelas 1 e 2 mostram que na reestruturação de algumas carreiras o peso do vencimento básico seguiu caindo, como é o caso da carreira de pesquisador em C\&T (representa, em média, um terço da remuneração efetivamente percebida) e fiscal agropecuário (menos da metade).

\section{CONCLUSÕES}

O artigo buscou levantar iniciativas do governo Lula da Silva em direção à construção de uma política de recursos humanos que tenha por finalidade a melhoria das condições e relações de trabalho no serviço público. Observou-se que vários passos foram dados e, apesar de recém-instituída, pode-se dizer que se avançou em relação ao período anterior. Mas, cabe observar, notam-se traços de continuidade em relação ao governo Cardoso e posições marcadas pela ambigüidade.

Houve um esforço de recompor os quadros do funcionalismo público em áreas específicas, como a do Ensino Superior e técnicotecnológico. Várias carreiras foram beneficiadas e puderam contar com concursos públicos (ainda que, na maioria dos casos, o número de servidores ainda esteja aquém do necessário). Registra-se, também, um esforço de (re)organização de inúmeras carreiras e de iniciativas no campo da qualificação dos servidores.

Do ponto de vista do relacionamento entre governo e representação sindical registram-se avanços, pois houve uma postura clara de negociação de ambas as partes. A instituição da MNNP é um claro indício da tentativa de dirimir conflitos por meio da negociação. Entretanto, a trajetória da MNNP reforça a leitura de que o Governo Lula da Silva empreende suas políticas públicas de modo ambíguo, ora avançando rumo a uma agenda mais progressista, afinada com os interesses dos movimentos sociais, ora insistente nos marcos fundamentais da agenda consolidada nos anos 1990, condicionando a totalidade da gestão aos limites fiscais. Se por um lado foi aberto um importante canal de solução para os embates que envolvem as relações de trabalho no setor público, bem como a construção de um fórum permanente de participação do servidor na atividade de repensar o próprio aparelho do Estado; por outro, as negociações não avançaram suficientemente, os compromissos governamentais com as demandas das entidades da bancada sindical não foram encaminhados, bem como foram estabelecidos constrangimentos legais que tramitam no Congresso Nacional que produzirão a inviabilidade para o sucesso de negociações pautadas em reajustes que superem as margens estabelecidas.

No que diz respeito à remuneração, houve um tratamento diferenciado entre as diversas carreiras do poder Executivo federal. Algumas lograram alcançar elevados índices de reajustes e conseguiram melhorar a estrutura da remuneração (com o abandono de formas variáveis de remuneração). Outras carreiras, no entanto, tiveram reforçado os mecanismos de remuneração variável. Nota-se que persiste, na estrutura remuneratória do serviço público, grande dispersão dos rendimentos entre as diversas carreiras. 
Darcilene Cláudio Gomes (darcilene.gomes@fundaj.gov.br)é Doutora em Economia pela Universidade Estadual de Campinas (Unicamp).

Leonardo Barbosa e Silva (barbosaesilva.leonardo@gmail.com) é Doutor em Sociologia pela Universidade Estadual Paulista (Unesp).

Sidartha Sória (sidartha.soria@unicamp.br) é Doutor em Sociologia pela Universidade Estadual de Campinas (Unicamp).

\section{REFERÊNCIAS BIBLIOGRÁFICAS}

BALTAR, P. E. A. 2003. O mercado de trabalho no Brasil dos anos 90. Campinas. Tese (LivreDocência em Economia). Universidade Estadual de Campinas.

BARBOSA E SILVA, L. \& SORIA E SILVA, S. 2006. Anatomia do governo Lula: o governo como condomínio de interesses. Trabalho apresentado no III Congresso Latino-Americano de Ciência Política, realizado em Campinas, de 4 a 6 de setembro. Digit.

CARVALHO FILHO, E. D. P. 2002. Evolução no emprego público no Brasil nos anos 90. Campinas. Tese (Doutorado em Economia). Universidade Estadual de Campinas.

DEDECCA, C. S. 2003. Anos 90: a estabilidade com desigualdade. In: PRONI, M. W. \& HENRIQUE, W. (orgs.). Trabalho, mercado e sociedade: o Brasil nos anos 90. São Paulo: UNESP.

GOMES, D. C. 2009. Estrutura produtiva e emprego industrial no Brasil dos anos 90. Campinas. Tese (Doutorado em Economia). Universidade Estadual de Campinas.

GOMES, M. B. 2006. Decifra-me ou te devorarei. A imagem pública de Lula no horário eleitoral nas campanhas presidenciais de 1989, 1994, 1998 e 2002. João Pessoa: UFRN.

MARQUES, R. M. 2000. Notas sobre a reforma previdenciária brasileira no contexto do neoliberalismo e da América Latina. Revista de Economia Política, São Paulo, v. 20 n. 1, p. 138-148, jan.-mar. Disponível em: http://www.rep.org.br/pdf/77-9.pdf. Acesso em: 28.abr.2012.
MARQUES, R. M. \& MENDES, A. 2004. O governo Lula e a contra-reforma previdenciária. São Paulo em Perspectiva, São Paulo, v. 18, n. 3, p. 3-15. Disponível em: http://www.scielo.br/pdf/spp/v18n3/ 24774.pdf. Acesso em: 28.abr.2012.

MATIJASCIC, M. 2002. Crise e reformas do complexo previdenciário no Brasil. Campinas. Tese (Doutorado em Economia). Universidade Estadual de Campinas.

MATTOS, F. A. M. 2005. A contribuição do emprego público na geração de postos de trabalho nos países desenvolvidos desde o pós-guerra. Análise Econômica, Porto Alegre, v. 23, n. 43, mar. Disponível em: http://seer.ufrgs.br/AnaliseEconomica/article/ view/10809/6419. Acesso em: 28.abr.2012.

MORAES, M. V. E.; SILVA, T. F. \& COSTA, P. V. 2008. O mito do inchaço da força de trabalho no Executivo Federal. Revista ResPvblica, Brasília, v. 7, n. 2, jul.-dez. Disponível em: http://www.anesp.org.br/ userfiles/respvblica 7 2.pdf. Acesso em: 28.abr.2012.

PESSOA, E. 2003. Estado, serviços e emprego público no Brasil: principais tendências nos anos 90. Trabalho apresentado no VIII Encontro Nacional de Economia Política, realizado em Florianópolis, de 17 a 20 de setembro. Digit.

QUADROS, W. J. 2003. Aspectos da crise social no Brasil dos anos 80 e 90. Campinas. Tese (Livre-Docência em Economia). Universidade Estadual de Campinas.

UEMA, J. K. 2005. O governo Lula e a reestruturação do serviço público federal. Brasília: Assessoria da Bancada do Partido dos Trabalhadores. 


\section{OUTRAS FONTES}

ADUFU. 2010. Informativo especial. Uberlândia: Associação dos Docentes da Universidade Federal de Uberlândia, n. 105.

BRASIL. 2009. Projeto de Lei Orçamentária 2010 - Mensagem Presidencial. Brasília: Ministério do Planejamento, Orçamento e Gestão. Disponível em: https:// www.portalsof.planejamento.gov.br/sof/ 2010/Mensagem_Presidencial_31_08.pdf/. Acesso em: 28.abr.2012.

BRASIL. MPOG. 2007. Governo investe em políticas de valorização do servidor. Disponível em: http://www.planejamento. gov.br/noticia.asp? $p=\operatorname{not} \& \operatorname{cod}=1753 \&$ cat $=26 \& \sec =11$. Acesso em: 28.abr.2012.

2010. Projeto proporá ao congresso regulamentação da negociação no serviço público. Disponível em: http://www. planejamento.gov.br/noticia.asp? $\mathrm{p}=$ not\&cod $=6043 \& \mathrm{cat}=26 \& \mathrm{sec}=11$. Acesso em: 28.abr.2012.

BRASIL. SECRETARIA DE ORÇAMENTO FEDERAL. 2009. Projeto de Lei Orçamentária 2009 prevê R \$ 119 bilhões em investimentos. 2008. Disponível em: https:/ /www.portalsof.planejamento.gov.br/ 20080827_02. Acesso em: 28.abr.2012.

BRASIL. MP-SEGES. 2003. Gestão pública para um Brasil de todos: um plano de gestão para o Governo Lula. Brasília: Ministério do Planejamento, Orçamento e Gestão.

BRASIL. MPOG-SRH. 2002. Tabela de remuneração dos servidores públicos federais. V. 10. Brasília: Ministério do Planejamento, Orçamento e Gestão. 2010a. Boletim estatístico de pessoal. Brasília: Ministério do Planejamento Orçamento e Gestão, v. 15, n. 167, mar.

2010b. Tabela de remuneração dos servidores públicos federais. Brasília, Ministério do Planejamento Orçamento e Gestão, v. 50.

CONDISEF. 2010. Revista Chapa, ano XX, edição especial, ago. Disponível em: ww w. cond sef.org.br/imagen s/ imprensadestaques/revista\%20Chapa.pdf. Acesso em: 28.abr.2012.

DIEESE. 2005. Despesa com pessoal e encargos sociais da União e outros indicadores. Brasília, ano I, n. 10, jun.

2007. O PAC e a questão dos servidores: Projeto de Lei Complementar à Lei de Responsabilidade Fiscal - LRF (Limite dos Gastos com pessoal do setor público). Nota técnica, n. 44. Disponível em: www. dieese.org.br/notatecnica/notatec 44 PACeServidores.pdf. Acesso em: 28.abr.2012.

IBGE. 2009. Pesquisa Nacional de Amostra de de Domicílios (2009). Disponível em: http:// www.ibge.gov.br/home/estatistica/populacao/ trabalhoerendimento/pnad2009/ Acesso em: 28.abr. 2012 .

MARE. 1995. Plano Diretor da Reforma do Estado. Brasília: Ministério da Administração Federal e da Reforma do Estado.

OCDE. 2004. Public sector modernization: modernizing public employment. Paris: OCDE. 


\section{WORKING CONDITIONS AND RELATIONS IN THE PUBLIC SECTOR: THE CASE OF THE LULA GOVERNMENT}

\section{Darcilene Cláudio Gomes, Leonardo Barbosa Silva and Sidartha Sória}

This article attempts an inventory of the numerous initiatives of the Lula government (2003-2010) with regard to the establishing of human resource policy and, in this regard, seeks to verify if there has been improvement in working conditions and relations in the Brazilian public sector. As of the 1990s and against the grain of the major growth of public employment over the previous six decades, Brazilian government adhesion to the principles of the "Washington Consensus" has made it clear how civil service becomes a crucial issue on the agenda of reforms deemed necessary to recover economic growth. Such governments have tended to deal with public employment as a fiscal problem and have acted in such as way as to restrict it. Simultanteously, work conditions and relations have become more precarious (as evidenced by the absence of inflation adjustments, the increase in variable forms of wages and salaries; increased temporary and subcontracted labor and authoritarian positions regarding labor unions). Through documentary and bibliographic research, we have been able to see that the restructuring of different careers, new employment openings, the creation of a National Board of Permanent Negotiation, social security system reform and selective wage readjustment show that ambiguity is the fundamental trait of human resource policies. This is due to the fact that improvements in civil servants' working conditions have been accompanied by the 
maintenance of a part of the conservative agenda of the 1990s, particularly that part that has sought to reproduce rigorous fiscal limits.

KEYWORDS: Public Employment; Labor Conditions; Collective Bargaining. 
LES CONDITIONS ET LES RELATIONS DE TRAVAIL DANS LE SERVICE PUBLIC : LE CAS DU GOUVERNEMENT LULA

\section{Darcilene Cláudio Gomes, Leonardo Barbosa Silva et Sidartha Sória}

Cet article a l'objectif de détailler les diverses initiatives du gouvernement Lula (2003-2010) par rapport à la mise en forme d'une politique de ressources humaines et, de cette façon, vérifier s'il y a eu une amélioration des conditions et relations de travail dans le secteur public brésilien. À partir des années 1990, et dans le sens contraire de la grande croissance de l'emploi public dans les six décennies précédentes, l'adhésion des gouvernements brésiliens aux principes du «Consensus de Washington » souligne le fonctionnalisme comme point fondamental dans l'agenda des réformes nécessaires à la reprise de la croissance économique. Ces gouvernements là se sont penchés sur le traitement de l'emploi public comme étant un problème fiscal et ont agi pour restreindre sa dimension. Simultanément, les conditions et relations de travail se sont présentées plus fragilisées (rendues évidentes par l'absence de réajustement de salaire; la croissance de formes variables de rémunération ; l'élargissement du cadre de travailleurs temporaires et externes, e avec l'attitude autoritaire devant la représentation syndicale). Avec une recherche documentaire et bibliographique, on pourra remarquer que la restructuration de nombreuses carrières, la reprise des concours, la création de la « Réunion Nationale de Négotiation Permanente », la réforme de la sécurité sociale et les réajustements selectifs des rémunérations manifestent l'ambiguïté comme une marque fondamentale des politiques de ressources humaines. Cela parce que, au même temps, les progrès des conditions de travail du serviteur public ont toujours été accompagnés par l'entretien d'une partie de l'agenda conservatrice des années 1990, surtout par rapport à la reproduction de limites fiscaux rigoureux.

MOTS-CLÉS : emploi public; conditions de travail; négotiation collective. 